обеспечивающий психолого-педагогическую поддержку семьи и повышение компетентности родителей в вопросах развития и образования ребенка в системе ДО. Именно такой метод обучения способствует повышению психолого-педагогической культуры родителей, от которой зависит успешность и результативность домашнего образования как вида образования, направленного на развитие личности ребенка в рамках индивидуальных образовательных траекторий на основе освоения образовательной программы дошкольной организации для достижения социально-нормативных возрастных характеристик в соответствии ФГОС ДО.

$$
* * *
$$

1. Веретенникова В. Б. Базовые компетенции субъектов образовательного процесса в системе современного дошкольного образования // Психология и педагогика: теоретические и практические аспекты современных наук : материалы XXXI междунар. науч.-практ. конф. - Москва. - 2015. - С 2738.

2. Веретенникова, В.Б. Индивидуальные образовательные траектории развития ребенка в системе дошкольного образования/ В.Б. Веретенникова // Качество Инновация Образование. - 2017. - № 1. C. $25-32$.

3. Веретенникова В.Б., Шихова О.Ф. Стратегические направления развития современной системы дошкольного образования// Современные проблемы науки и образования. - 2015. - № 6; URL: http://www.science-education.ru/130-23303 (дата обращения: 30.11.15)

4. Веретенникова В.Б. Структурно-функциональная модель качества компетентностно-ориентированного образовательного процесса в системе дошкольного образования/Казанский педагогический журнал. 2015. № 5. Часть 2. - С. 76-81.

5. Веретенникова В. Б. Структура компетенций субъектов образовательного процесса в современной системе дошкольного образования // Национальная Ассоциация Ученых. - 2015. - № 4-3 (9). - С. 69-72.

6. Веретенникова В. Б. Элементы дистанционного курса как средство обучения родителей в современной системе дошкольного образования // Тенденции науки и образования в современном мире. -2016 . - № 18-1. - C. 9-14.

7. Куликова Т. А. Семейная педагогика и домашнее воспитание : учебник. - Москва : Издательский центр «Академия», 1999. - 232 с.

8. Примерная основная образовательная программа дошкольного образования [Электронный ресурс] Режим доступа: http://gosreestr.ru/wp-content/uploads/2015/08/primernaja-osnovnaja-obrazovatelnajaprogramma-doshkolnogo-obrazovanija.pdf (15.09.2017).

\title{
Иванова Н.В. \\ Роль средств массовой информации в решении проблемы суицида среди подростков
}

Кубанский государственный университет физической культуры, спорта и туризма

(Россия, Краснодар)

doi: $10.18411 / s r-10-02-2018-24$

idsp: 000001:sr-10-02-2018-24

\section{Аннотация}

В статье представлен анализ эпидемиологии суицидов в мире, Российской Федерации, Краснодарском крае среди детей и подростков, приведены сведения, полученные в ходе анализа данных Всемирной организации здравоохранения, сформулированы причины различий между мужчинами и женщинами по частоте суицидов, представлена модель работы по профилактике самоубийств во всем мире. В работе также проанализированы среднестатистические показатели суицидов среди детей в возрасте 10-14 лет и молодежи 15-16 лет в Российской Федерации, Краснодарском крае, определена роль СМИ в решении проблемы суицида среди подростков. Сформулированы основные причины, влияющие на совершение самоубийств среди подростков.

Ключевые слова: средства массовой информации, суицид, подростки, молодежь 
Исторически значимое событие произошло в Женеве на 66-й сессии Всемирной ассамблеи здравоохранения, проходившей в мае 2013 года. Впервые в рамках деятельности данной организации был разработан и принят общим голосованием План работы в области психического здоровья населения. который предполагает комплекс мероприятий, направленных на нормализацию психического здоровья населения в период 2013-2020 гг. Проблема суицидов и их предотвращения является основой данного стратегического задания. В документе поставлены перспективные цели снижения частоты суицидов до $10 \%$ в мире.

Российская статистика приводит цифры: на сегодняшний день около $13 \%$ молодых людей (от общего числа умерших от неестественных причин) расстаются с жизнью добровольно. Приведенные данные служат причиной углубленного рассмотрения вопроса о суицидальных тенденциях поведения в подростковом возрасте.

Объект исследования - деятельность средств массовой информации в решении проблем суицида среди подростков.

Предмет исследования - факторы и причины, влияющие на совершение самоубийств среди подростков.

Цель исследования заключалась в определении роли средств массовой информации в решении проблемы суицида среди подростков.

Задачи исследования:

1. Проанализировать эпидемиологию суицидов в мире, Российской Федерации, Краснодарском крае среди детей и подростков.

2. Определить роль средств массовой информации в решении проблемы суицида среди подростков.

3. Сформулировать группу факторов и основные причины, влияющие на совершение самоубийств среди подростков в Краснодарском крае.

В 2013 г. Департамент психического здоровья и токсикомании ВОЗ приступил к проведению глобального опроса по предотвращению самоубийств, с целью получения информации о национальных стратегиях и деятельности в этой сфере. Анализируя, представленную на рисунке 1 информацию, можно сделать следующее заключение.

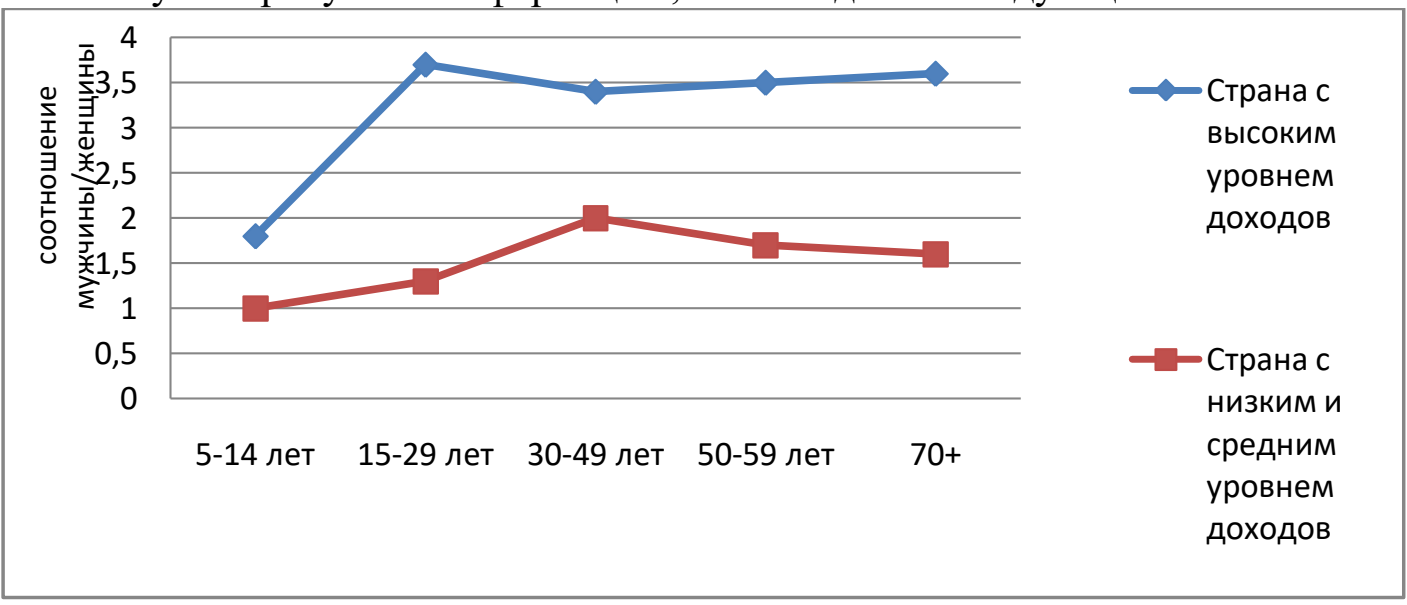

Рисунок 1. Соотношение мужчины/женщины в показателях частоты самоубийств по возрастным группам и уровню доходов стран, 2015 г.

В течение многих лет было принято считать, что в мировом масштабе мужчины совершают самоубийства втрое чаще, чем женщины. Однако это я наблюдается, главным образом, в странах с высоким уровнем доходов, где в 2015 г. соответствующее соотношение значений стандартизированного по возрасту показателя частоты самоубийств составило 3,5 [2].

В странах с низким и средним уровнем доходов соотношение мужчины/женщины составляет всего лишь 1,6; иными словами, мужчины совершают самоубийства на $57 \%$ 
чаще, чем женщины. Также следует отметить, что различия отмечаются и в возрастном аспекте.

Так, почти во всех регионах мира наименьшая частота самоубийств наблюдается среди детей младше 15 лет, а наибольшая - среди лиц в возрасте 70 лет и старше, как среди мужчин, так и среди женщин.

Прослеживается и другая динамика, которая напрямую зависит от уровня доходов населения. Главное различие между странами с высоким уровнем доходов и стран с низким и средним уровнем доходов состоит в том, что в странах с низким и средним уровнем доходов значительно выше частота самоубийств среди лиц молодого возраста и пожилых женщин. В богатых же странах гораздо больше самоубийств приходится на мужчин среднего возраста [4.]

Подводя итог, можно заключить, что при анализе частоты суицидов мужчин и женщин были выявлены причины этих различий: гендерное неравенство, которое наблюдается во многих странах; различные социальные способы и возможности разрешения конфликтов; свобода в приобретении и употреблении алкоголя; доступность и досягаемость средств совершения суицида; публичная огласка в средствах массовой информации.

В 2015 г. самоубийства составили 1,4\% смертей в мире, заняв 15-е место среди всех причин смерти.

В целом среди молодежи от 15 до 29 лет самоубийства составляют 8,5\% всех смертей, являясь второй по значимости причиной смерти (после дорожно-транспортных несчастных случаев) [1].

Всесторонний обзор проблемы самоубийств и суицидальных попыток, а также анализ работы по профилактике самоубийств во всем мире определил научно обоснованные подходы к формированию политики и разработке программ по предупреждению самоубийств, которые могут быть адаптированы к различным условиям.

На рисунке 2 представлена модель работы по профилактике самоубийств во всем мире.

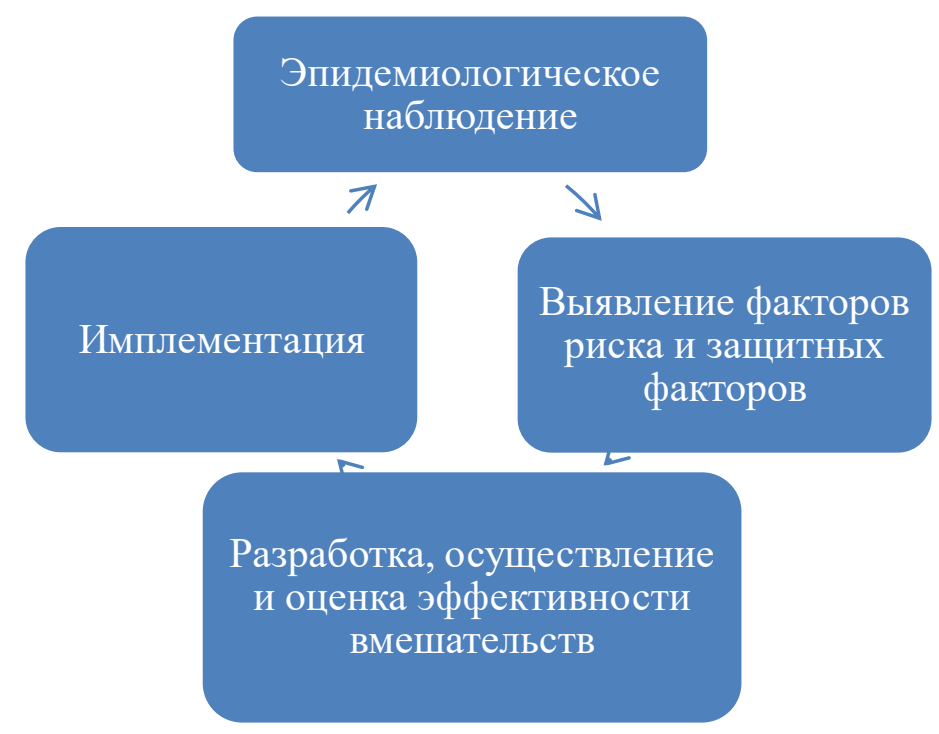

Рисунок 2. Модель работы по профилактике самоубийств в мире

Профилактика начинается с эпидемиологического наблюдения с целью определить проблему и понять ее; за этим следует идентификация факторов риска и защитных факторов (а также эффективных вмешательств); завершающий этап - принятие конкретных мер, включающих оценку эффективности и наращивание масштабов вмешательств, с последующим повторным мониторингом и действиями на основе его результатов. 
Всеобъемлющая концептуальная структура - в идеале это всесторонняя национальная стратегия - должна быть создана с учетом культурных особенностей, основана на всей необходимой информации и ставить целью управление процессами разработки, реализации и оценки с опорой на перспективное видение, политическую волю, лидерство, вовлечение заинтересованных сторон и, наконец, что не менее важно, финансирование.

По данным ВОЗ, Российская Федерация относится к числу стран, имеющих Национальную стратегию предупреждения самоубийств.

Анализируя исторический аспект, было выявлено, что царская Россия - страна с низким уровнем суицидов. Такая ситуация обусловлена несколькими факторами: религиозностью, православная вера запрещает накладывать на себя руки; лица, совершившие пробный поступок преследовались по закону. Но уже через 100 лет, в конце $\mathrm{XX}$ века, в Российской Федерации был зафиксирован настоящий социальный взрыв по частоте самоубийств.

Уполномоченная при Президенте РФ по правам ребенка А. Кузнецова заявила о росте количества детских самоубийств в 2016 году сразу на 57 \%. Одной из причин такого положения детский омбудсмен назвала лавинообразное распространение «групп смерти».

По мнению Е. Андреева, заведующего международной лабораторией исследования населения и здоровья Высшей школы экономики, приведенные омбудсменом данные не содержат возраста совершивших суицид.

Рассматривая статистические показатели суицидов детей в РФ, можно констатировать выраженную динамику снижения изучаемых детерминант (рис. 3). Среднестатистические значения представлены без данных Республики Крым.

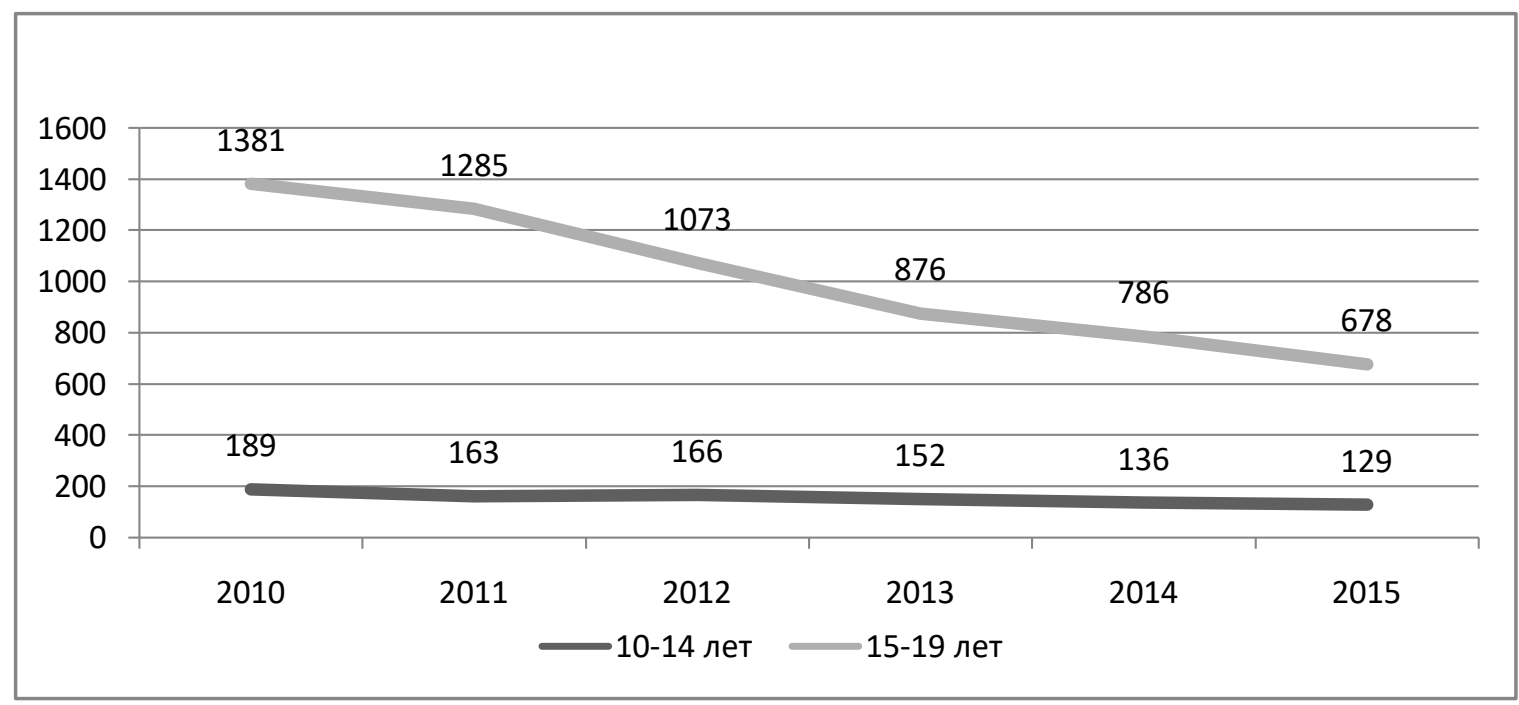

Рисунок 3. Среднестатистические показатели суицидов среди детей в возрасте 10-14 лет и молодежи 1516 лет (по данным Международной лаборатории исследования населения и здоровья Высшей школь экономики, 2016 г.)

При переводе статистических показателей в количество случаев суицида на 100 тысяч населения в каждой возрастной группе, также прослеживается устойчивая динамика снижения (рис. 4). Среднестатистические значения представлены без данных Республики Крым. 


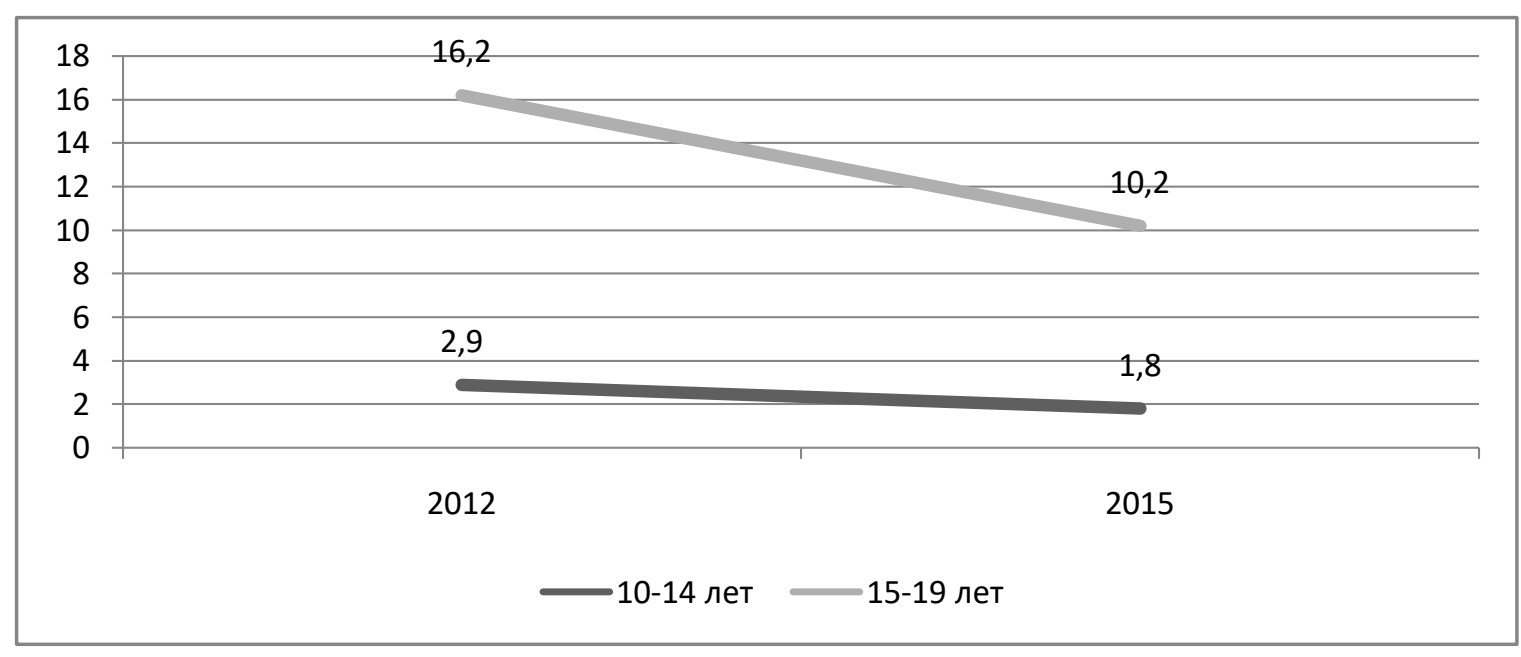

Рисунок 4. Количество случаев суиичдов среди детей в возрасте 10-14 лет и молодежи 15-16 лет на 100 тыс населения (по данным Международной лаборатории исследования населения и здоровья Высшей школьл экономики, 2016 г.)

В Краснодарском крае ситуация от всероссийской не отличается, тем не менее прослеживается динамика снижения количества самоубийств среди детей, подростков и молодежи. В крае лишили себя жизни 14 подростков и 15 детей пытались по собственной воли лишить себя жизни.

Детский омбудсмен заявила, что в Краснодарском крае и г. Краснодаре систематически проводятся главами муниципалитетов совещания, в повестке дня которых стоят вопросы, связанные с проблемами воспитания детей и подростков, осуществления мероприятий по борьбе с незаконным оборотом наркотиков, преступлениями против личности ребенка.

В Краснодарском крае работает выездной консультативный кабинет профилактики суицида, деятельность которого, направлена на работу с подростками и молодежью.

Рассматривая психологический портрет подростка и его психо-физиологические особенности, нами было выяснено, что СМИ играют огромную роль в его жизни. Так именно они показывают, как себя нужно вести, какие ценности преобладают в обществе. Конечно же, нельзя говорить, что ребенка воспитывает телевизор или Интернет, но это влияние слишком велико, чтобы на него не обращать внимание.

Анализ научно-методической литературы позволил определить факторы, которые влияют на неокрепшую психику ребенка и подростка в частности. Это и характер получаемой информации, и психологические, социальные особенности конкретного индивида и др.

Многие ученые подтверждают тот факт, что именно средства массовой информации распространяют идеи о том, как лучше, быстрее и безболезннее уйти в мир иной.

Существует масса суицидогенных ресурсов, романтизирующих самоубийство, призывающих к уходу из жизни, предоставляющих рекомендации по способам и разнообразным атрибутам суицида. СМИ в большинстве случаев представляют информацию о самоубийствах абсолютно недопустимыми методами, придавая ей сенсационный характер [3].

Таким образом, проблема суицидального поведения подростков обусловлена комплексом факторов объективного и субъективного характера, и решать ее можно только путем объединения усилий и согласованных действий специалистов разных ведомств, оказывающих социальную, правозащитную, медицинскую, психологическую, информационную и другие виды помощи. 
Проведенное социологическое исследование позволило сформулировать основные рекомендации, способствующие оказанию помощи ребенку и родителям:

- постараться войти в доверие к подростку, решившемуся на самоубийство или на ее попытку;

- понять, что несовершеннолетний подросток - личность и постараться строить общение на равных;

- серьезно подходить к возникшей ситуации, подросток может в любое время решиться на самоубийство;

- строить доверительные отношения;

- научиться слышать и слушать подростка;

- не спорить, не давать преждевременных оценок и заключений, дать ребенку выговориться;

- не перебивать, не задавать вопросов;

- не утешать, не дослушав;

- быть искренним, без фальши, с вниманием отнестись к ситуации и проблеме ребенка;

- постараться дать анализ сложившейся ситуации, рекомендовать подростку пути выхода из нее;

- не показывать испуга или недоверия по отношению к подростку;

- стараться ребенка не оставлять одного, наедине со своими мыслями;

- обратиться в специальные службы социальной помощи;

- помнить, что жизнь - величайшая ценность данная ребенку, и ваша задача сохранить ее.

\section{$* * *$}

1. Дмитриева Т.Б. Психическое здоровье и общественная безопасность. / /Т.Б. Дмитриева. Екатеринбург, 2008.

2. Матяш А.А. Превенции суицидов. Практическое руководство. / А.А. Матяш, П.А. Матяш. // Сборник работ. Электронное издание. - Магнитогорск, 2016.

3. Статистические показатели. Электронный ресурс. Официальный сайт Федеральной службы государственной статистики (Росстат).

4. http://www.euro.who.int/_data/assets/pdf_file/0008/257606/Suicide-report-a-global-imperativeRus.pdf?ua $=1 \& u a=1$

Литвак М.М.

Обучение через науку: использование программного пакета ChemOffice при изучении эйкозаноидов

Белгородский государственный нащиональный исследовательский университет», НИУ «БелГУ»

(Россия, Белгород)

doi: $10.18411 / \mathrm{sr}-10-02-2018-25$

idsp: 000001:sr-10-02-2018-25

Аннотация

В работе показано как с помощью программного пакета ChemOffice можно успешно решать ряд проблемных вопросов обучения студентов, в частности, касающихся строенияэйкозаноидов. Таким образом успешно реализовать один из методических приемов образования - обучение через науку.

Ключевые слова: эйкозаноиды, конформация, ChemOffice, обучение через науку, компьютерные технологии. 